\title{
DANDY-WALKER MALFORMATION: A RARE CONGENITAL ANOMALY
}

Uroos Fatima ${ }^{1}$, Satish Arakeri $^{2}$, Ram Kumar K. R ${ }^{3}$, Roopa $\mathrm{K}^{4}$

\section{HOW TO CITE THIS ARTICLE:}

Uroos Fatima, Satish Arakeri, Ram Kumar K. R, Roopa K. "Dandy-Walker Malformation: A Rare Congenital Anomaly". Journal of Evolution of Medical and Dental Sciences 2014; Vol. 3, Issue 32, August 04;

Page: 8761-8765, DOI: 10.14260/jemds/2014/3119

INTRODUCTION: Dandy Walker Malformation (DWM) is a congenital malformation involving the cerebellum and fluid filled spaces around it. A key feature of this syndrome is partial or complete absence of a part of brain located between two cerebellar hemispheres ie. cerebellar vermis.(1) Dandy walker malformation was originally described in 1887 by Sutton and further characterized by Dandy and Blackfan in 1914 followed by Tagart and Walker in 1942. Benda finally labeled this disease as Dandy Walker in 1954.(2) Since the original description, additional studies have reported on various morphological features of this syndrome. It is a genetically sporadic disorder that occurs one in every 30,000live births.(3) Because of its rarity, here we report a case of DWM, in a fetus in which the diagnosis was made prenatally on USG. Later on, MTP was done by expulsion. Fetus was sent for autopsy to rule out other associated congenital abnormalities.

CASE REPORT: A 29year old lady gravida2, para 1 with no live issue reported for routine antenatal checkup at 18 weeks of gestation. Her haematological and biochemical profile were within normal limits. Her blood group was 0 -ve. Her previous issue aborted spontaneously at 6weeks of gestation. No anti $\mathrm{D}$ was given at that time.

USG reported live18wk5d fetus in breech presentation with major congenital anomaly of DWM. There was a large posterior fossa cyst (Figure 1) with proximal ventriculomegaly in the brain. (Figure 2) The patient also had oligohydramnios (AFI 5.2). Fetal parameters on USG were:

BPD-4.9cm (20wk6d); HC-17.6cm(20wk1d); AC-12.0cm(17wk5d);FL-2.0cm(16wk2d);EFW193gm+-28gm. Head parameters corresponded with 20weeks gestation which was abnormal. HC/AC ratio-1.4; FL/HC ratio-12\%; FL/AC-17\% were reported abnormal.

Autopsy Findings: A dead male fetus was received weighing 185gm (Figure 3). HC was $16 \mathrm{~cm}$ which was large for gestational age (Figure 3). Other parameters were CRL-18cms; CHL-23cms; Abd girth at umbilicus $-10 \mathrm{cms}$. Length of umbilical cord $-3 \mathrm{cms}$. Cut surface showed presence of three vessels.

Cut surface of brain showed markedly dilated ventricles forming a cystic cavity in the midline extending up to posterior fossa. Surrounding brain parenchyma was thinned out.(Figure 4) Outer surface showed prominent vessels.

No other apparent internal congenital abnormality was evident.

DISCUSSION: DWM is a rare congenital malformation that involves the cerebellum and fourth ventricle. It is characterized by agenesis or hypoplasia of cerebellar vermis, cystic dilatation of the fourth ventricle and enlargement of the posterior fossa. Other concomitant malformations may also be present along with but these three features define DW malformation.

Around $70-90 \%$ patients have hydrocephalus which develops postnatally. DWM may also be associated with atresia of foramen of Magendie and possibly foramen of Luschka.(4) Not until 1954did 
Benda first explain that atresia of cerebellar outlet foramina is not an essential feature of this condition and suggested the now widely accepted term Dandy- Walker Malformation.(5)

The term Dandy- Walker represents not a single entity but several abnormalities of brain development that coexist. These posterior fossa cystic malformations have been divided into DW Malformation; DW Variant; mega cisterna magna and posterior fossa arachnoid cyst. DW Malformation; DW Variant and Mega cisterna magna currently represent a continuum of developmental anomalies on a spectrum termed as DW Complex.(6)

DW malformation is characterized by enlarged posterior fossa; high position of the tentorium with upward displacement of lateral sinus; varying degrees of vermian aplasia or hypoplasia and cystic dilatation of the fourth ventricle that nearly fills the entire posterior fossa.

DW variant consists of vermian hypoplasia and cystic dilatation of fourth ventricle without enlargement of posterior fossa.

Mega cisterna magna consists of enlarged posterior fossa secondary to an enlarged cisterna magna with normal cerebellar vermis and fourth ventricle.(7)

Table: Associated Findings in DW Syndrome:

\begin{tabular}{|l|l|}
\hline \multicolumn{1}{|c|}{ CNS Findings } & \multicolumn{1}{c|}{ Non CNS findings } \\
\hline Dysgenesis of corpus callosum & Orofacial deformities \\
\hline Lipoma of corpus callosum & cleft palate \\
\hline Holoprosencephaly & polydactyly \\
\hline Porencephaly & Syndactyly \\
\hline Dysplasia of cingulate gyrus & Cardiac anomalies \\
\hline Schizencephaly & $\begin{array}{l}\text { Urinary tract anomalies } \\
\text { (polycystic kidneys) }\end{array}$ \\
\hline polymicrogyria & Cataract \\
\hline Cerebellar heterotopia & Retinal dysgenesis \\
\hline Occipital encephalocoele & Choroid coloboma \\
\hline Microcephaly & Facial haemagioma \\
\hline Dermoid cysts & Hypertelorism \\
\hline $\begin{array}{l}\text { Malformation of cerebellar folia; } \\
\text { inferior olivary nucleus }\end{array}$ & Meckel-Gruber syndrome \\
\hline Hamartoma of tuber cinereum & Neurocutaneous melanosis \\
\hline Syringomyelia & \\
\hline Klippel-Feil deformity & \\
\hline Spina bifida & \\
\hline Lumbosacral meningocoeles & \\
\hline Spinal Lipoma & \\
\hline
\end{tabular}

Dandy-Walker Syndrome (DWS) is one such disease considered to be a part of emerging class of diseases called Ciliopathies. Underlying cause may be a dysfunctional molecular mechanism in the primary cilia structure of the cell, organelles which are present in many cellular types throughout the human body. The cilial defects affect numerous critical developmental signaling pathways which are 
essential to cerebellar development and thus offers a plausible hypothesis for multi syndrome nature of large set of syndromes and diseases in DWS.(8)

DWM occurs as an autosomal dominant inherited disorder with a frequency of about 1 in 25000 -35000 pregnancies. (9) The gene locus for DWM is 3q24 and the presence of multiple congenital defects associated with it shorten the life span.(1) It has been reported most often in people with trisomy 18 but can occur in people with trisomies 13, 21, 9 also. Additionally DWS has been reported in fetus or newborns with triploidy too.(10)

Darbo et al found mutations in extracellular matrix genes N1D1 and LAMC1 causing autosomal dominant DWM and occipital cephalocoeles in a family by performing whole exome sequencing. Structural modeling of N1D1-LAMC1 complex demonstrated that each mutation disrupts the interaction. These findings implicate ECM in pathogenesis of DW spectrum disorders. ${ }^{(10)}$

Cases of DWM are reported more in females (11) whereas our case was a male fetus. Various predisposing factors have been reported such as Intrauterine infections, cranial trauma, chronic disturbances in CSF pressure, persistence of embryonic tissue, vascular lesions, teratogens, rubella, alcohol and maternal diabetes. ${ }^{(9)}$

DWM is best diagnosed with the help of Ultrasound and MRI.(7) Ultrasound is routinely used in antenatal period as a screening modality. Prenatal diagnosis of DWM should not be made before $18^{\text {th }}$ week of gestation because cerebellar vermis may be incomplete at that time.(7)

Although great variability exists in intracranial findings in fetuses, sagittal measurement exceeding $10 \mathrm{~mm}$ helps confirm the presence of DW cyst. In our case the biparietal diameter on USG was $4.9 \mathrm{~cm}$ and Head circumference was $17.6 \mathrm{~cm}$ which was more than the gestational age.

Syndromes associated with DWM include PHACE syndrome (posterior fossa abnormalities, haemagiomas, arterial anomalies, coarctation of aorta, cardiac defects and eye abnormalities) and Ellis-Van Creveld Syndrome.(12)

Historically, DWM was found incidentally or on autopsy.(13) Nowadays different neuroimaginary techniques have enabled the diagnosis to be made prenatally as was done in our case.

CONCLUSION: Dandy Walker Malformation is a condition which can be effectively diagnosed by imaging modalities, especially in antenatal period with a proper antenatal checkup and sonography. If diagnosed prenatally, the couple can be advised for MTP as the morbidity and mortality associated with this condition are high. Further genetic counseling and care in subsequent pregnancies can be taken up.

\section{REFERENCES:}

1. National Institute of Neurological Disorders and Stroke, "NINDS Dandy Walker Syndrome Information page. Available from: http://ninds.nih.gov/disorders/dandywalker/dandywalker.htm. (Last updated September 16, 2008).

2. Dandy WE, Balckfan KD. Internal hydrocephalus: an experimental, clinical and pathological study. Am J Dis Child. 1914; 8: 406-82.

3. Alam A, Chander BN, Bhatia M. Dandy Walker variant: Prenatal diagnosis by Ultrasonography. Med J Armed Forces India.2004; 60: 287-9. 
4. Cakmak A, Zeyrek D, Cekin A, Karazeybek H. Dandy-Walker syndrome together with occipital encephalocoele. Minerva Paediatr. 2008; 60 (4): 465-8.

5. Benda CE. The Dandy-Walker syndrome or the so called atresia of foramen Magendie. J Neuropathol Exp Neurol. 1954; 13 (1): 14-29.

6. Sasak i-Adams D, Elbabaa SK, Jewells V, Carter L, Campbell JW, Ritter AM. The Dandy Walker variant: a case series of 24 paediatric patients and evaluation of associated anomalies, incidence of hydrocephalus, and developmental outcomes. J Neurosur Paediatrics. 2008; 2 (3): 194-9.

7. Imaging in Dandy-Walker Malformation. Available from http://www.emedicine.medscape.com/article/408059-overview.

8. Badano, Jose L., Norimasa M, Phil L B, Nicholas K. The ciliopathies: an emerging class of human genetic disorders.Annual Review of Genomics and Human Genetics.2006; 7: 125-48.

9. Cardoso J, Lange MC, Lorenzoni PJ, Scola RH, Werneck LC. Dandy Walker Syndrome in adult mimicking myasthaenia gravis. Arq Neuropsiquiatr.2007; 60: 287-9.

10. Darbo BW, Mahajan VB, Gakhar L, Skeie JM, Campbell E, Wu S et al. Mutations in extracellular matrix genes N1D1 and LAMC1 cause autosomal dominant Dandy-Walker Malformation and occipital cephalocoeles. Hum Mut at. 2013; 34 (8): 1075-9.

11. Osenbach RK, Menezes AH. Diagnosis and management of Dandy-Walker malformation:30 years of experience. Paediatr Neurosurg. 1992; 18: 179-89.

12. Jone's KL. Smith's recognisable patterns Human Malformation. 5thedn.ElsevierSaunders; 1997.

13. Engelhard HH, Meyer JR. Adult onset presentation of Dandy-Walker variant in siblings. Surg.Neurol. 1995; 44: 43-7.

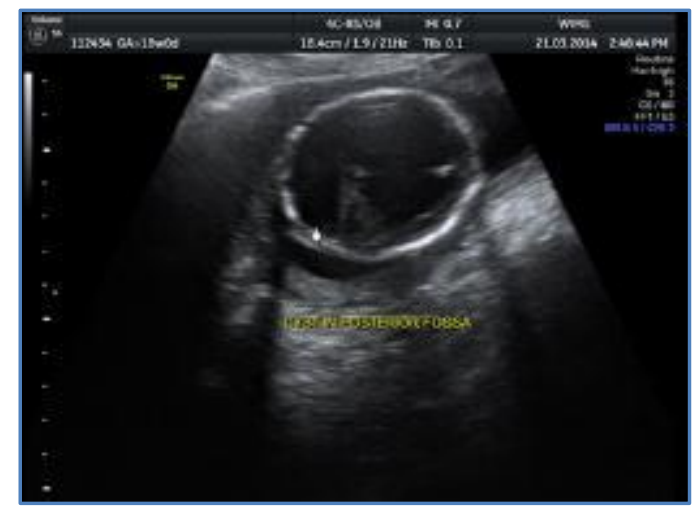

Fig. 1: USG showing posterior fossa cyst

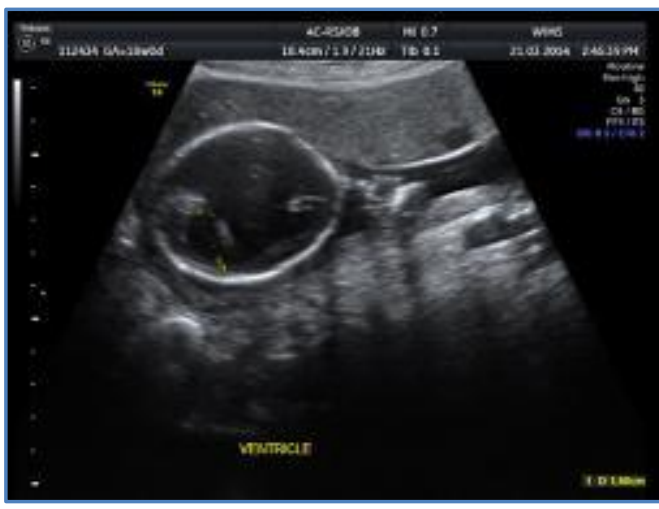

Fig. 2: USG showing ventriculomegaly 


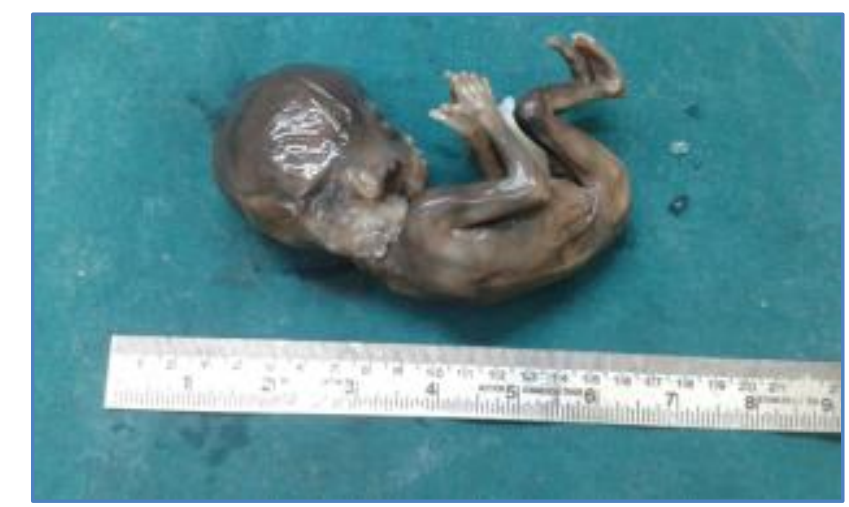

\section{Fig. 3: Gross specimen of fetus with enlarged head (large for gestational age)}

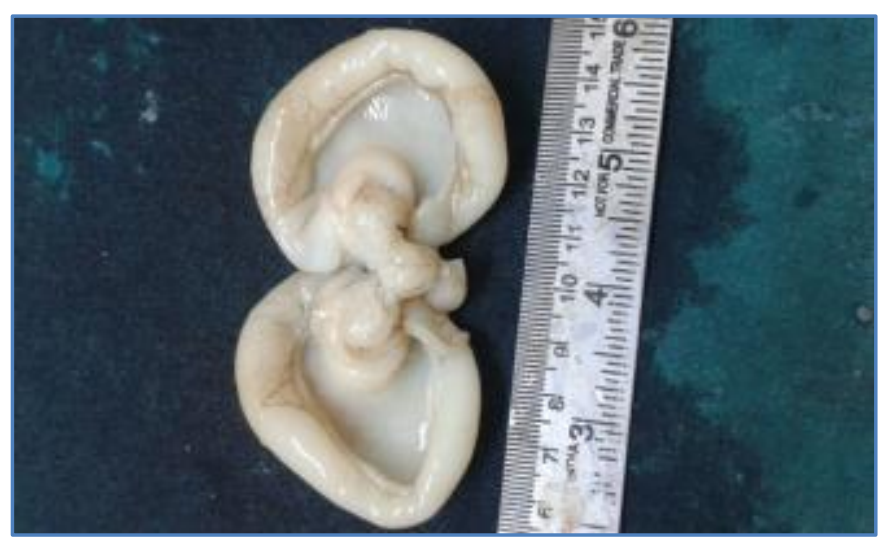

\section{Fig. 4: Gross specimen of fetal brain showing markedly} dilated ventricles with thinned out parenchyma

\section{AUTHORS:}

1. Uroos Fatima

2. Satish Arakeri

3. Ram Kumar K. R.

4. Roopa K.

\section{PARTICULARS OF CONTRIBUTORS:}

1. Associate Professor, Department of Pathology, DM Wayanad Institute of Medical Sciences.

2. Assistant Professor, Department of Pathology, DM Wayanad Institute of Medical Sciences.

3. Professor and HOD, Department of Pathology, DM Wayanad Institute of Medical Sciences.

4. Assistant Professor, Department of Radiology, DM Wayanad Institute of Medical Sciences.

\section{NAME ADDRESS EMAIL ID OF THE} CORRESPONDING AUTHOR:

Dr. Uroos Fatima,

Department of Pathology,

DMWIMS,

Mepaddi-673577, P.0,

Wayanad, Kerala.

Email: fatimauroos@gmail.com

Date of Submission: 17/07/2014.

Date of Peer Review: 18/07/2014.

Date of Acceptance: 28/07/2014.

Date of Publishing: 02/08/2014. 